\title{
UM MÉTODO EFICIENTE PARA ISOLAMENTO E PURIFICAÇÃO DA PODOFILOTOXINA A PARTIR DO EXTRATO DE PODOFILINA E ALGUMAS TRANSFORMAÇÕES QUÍMICAS SOB IRRADIAÇÃO DE MICROONDAS
}

\author{
An Efficient Method for Isolation and Purification of Podophyllotoxin from Podophyllin \\ Extract and Some Chemical Transformations under Microwave Irradiation
}

\section{Dênis Pires de Lima*; Lucinéia Vizzotto; Antônio Marcos Jacques Barbosa; Vânia Gomes Mariano; Adilson Beatriz}

Departamento de Química, Centro de Ciências Exatas e Tecnologia, Universidade Federal de Mato Grosso do Sul Av. Senador Filinto Müller, 1555 - CEP 79074-760 - Campo Grande, MS.

*Autor para correspondência e-mail: dlima@nin.ufms.br

Recebido em 31/01/2006- Aceito em 04/07/2006

RESUMO: A podofilotoxina foi isolada e purificada a partir do extrato de podofilina usando um método de baixo custo e eficiente, que rapidamente permitiu a obtenção da substância na sua forma pura. O método envolveu o uso de amido de milho como um meio de adsorção a fim de favorecer a separação da podofilotoxina de outros constituintes que estão presentes no extrato. O produto isolado foi submetido à irradiação de microondas, na presença de cloridrato de piridina, visando uma reação de desmetilação branda e seletiva sob condições livre de solvente.

PALAVRAS-CHAVE: Podofilotoxina, isolamento, podofilina, reação sob microondas.

ABSTRACT: Podophyllotoxin was isolated and purified from podophyllin extract by using an efficient and inexpensive method that rapidly allowed the obtaining of the pure compound. The method involves the use of cornstarch as adsorption medium in order to favor the separation of podophyllotoxin from the other constituents that are present in the extract. The isolated product was submitted to microwave irradiation, in the presence of pyridinium hydrochloride, in order to attempt mild selective demethylation under solvent free condition.

KEYWORDS: Podophyllotoxin, isolation, podophyllin, microwave reaction

\section{INTRODUÇÃO}

A podofilina é uma mistura de resinas obtida a partir do rizoma seco e das raízes das plantas Podophyllum peltatum L. e Podophyllum emodi Wall. Ex Royle, as quais são encontradas na América do Norte e no Himalaia, respectivamente (MILLER, 1985). A podofilotoxina 1 é o principal componente bioativo da podofilina. O composto tem sido extensivamente estudado e os trabalhos científicos publicados enfocam principalmente os seus derivados que são poderosos agentes antitumorais, tais como etoposídeo (VP-16-213) 3 e teniposídeo (VM-26) 4 (YONGJAE, 2005; PINTO et al., 2002; AJANI et al., 1999; STÄHELIN \& WARTBURG, 1991; HORWTIZ \& LOIKE, 1977; LOIKE \& HORWTIZ, 1976a e 1976b) (Fig. 1). Os compostos 4'-O-desmetil 2 ou 6 são intermediários-chave para a síntese dos agentes antitumorais 3 e 4 e as suas preparações são laboriosas e de alto custo. 
<smiles>[R]Oc1c(OC)cc([C@H]2c3cc4c(cc3[C@@H](O)[C@@H]3COC(=O)[C@@H]23)OCO4)cc1OC</smiles>

1: $R=-M e$
2: $R=-H$

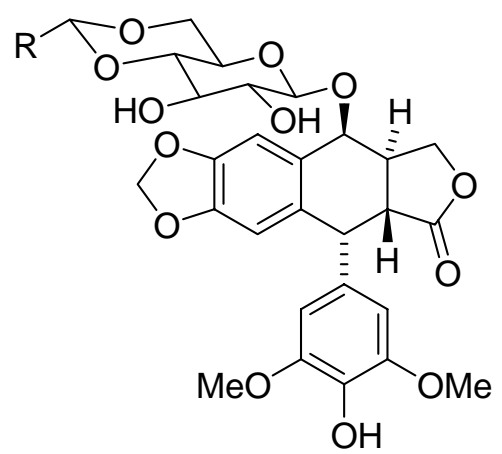

3: $\mathrm{R}=-\mathrm{Me}$
4: $\mathrm{R}=$<smiles>[R]c1c(OC)cc([C@H]2c3cc4c(cc3C(=O)[C@@H]3COC(=O)[C@H]32)OCO4)cc1OC</smiles>

5: $\mathrm{R}=-\mathrm{Me}$

6: $\mathrm{R}=-\mathrm{H}$

Figura 1. Estruturas químicas da podofilotoxina (1) e de alguns de seus derivados.

Nosso grupo de pesquisa tem realizado estudos de transformações estruturais de 1 para, eventualmente, encontrar análogos com propriedades biológicas importantes (LIMA et al., 1994). A podofilotoxina é usualmente isolada a partir do extrato etanólico da podofilina por extração e fracionamento com solventes, seguido por sucessivas recristalizações e técnicas cromatográficas. Os inconvenientes associados a esses métodos, tais como o uso de grande quantidade de solvente orgânico, alto custo das técnicas de cromatografia, tempo e dificuldade de purificação do material depois de isolado, encorajou-nos a investigar uma nova metodologia para rapidamente obter a podofilotoxina pura visando seu uso para transformações químicas.

Neste contexto, desenvolvemos um método mais eficiente para isolar o composto $\mathbf{1}$, fazendo uso de amido de milho como material adsorvente. O método foi inspirado no procedimento no qual está descrito o isolamento de $1 \mathrm{com}$ a ajuda da amido de arroz (DE AMBROSI, 1954).

\section{MATERIAL E MÉTODOS}

Reagentes: Os solventes e sílica para cromatografia do tipo flash foram adquiridos da Acros Organic Company e foram usadas como recebidas. Podofilina e amido de milho foram obtidos da CENNABRAS Ind. Com. Ltda.

Isolamento e Purificação: Isolamento e purificação da podofilotoxina - $100 \mathrm{~g}$ de podofilotoxina comercial são misturadas com $400 \mathrm{~g}$ de amido de milho. O material é homogeneizado, usando-se um mortar com pistilo e então adicionado a $1 \mathrm{~L}$ de clorofórmio. A mistura é agitada por 15 minutos e filtrada sob vácuo. Três extrações podem ser feitas para assegurar um bom rendimento. Os filtrados são reunidos e o solvente é evaporado em rotaevaporador. O resíduo resultante é um material esponjoso, o qual deve ser tratado com $30 \mathrm{~mL}$ de etanol 95\% para que ocorra a cristalização da podofilotoxina. Nesta etapa, 1 é isolado com poucas impurezas que são finalmente removidas por filtração em cromatografia do tipo flash, usando-se como eluente uma mistura de hexano/acetato de etila 3:2. O rendimento de podofilotoxina é de $45-48 \mathrm{~g}$ (Ponto de Fusão: $118^{\circ} \mathrm{C}$ ).

Transformações Químicas: Geral - As irradiações de microondas foram feitas usando-se um forno de microondas comercial (marca Consul, $240 \mathrm{~W}$ ) operando a freqüências variadas e os produtos foram analisados por espectroscopia de RMN de ${ }^{1} \mathrm{H}$ e de ${ }^{13} \mathrm{C}$.

Podofilotoxona (5) e cloridrato de piridina foram preparados por métodos usuais (LIMA et al., 1994; VOGEL, 1967).

Reação modelo do ácido 3,5-Dimetóxibenzóico Assistida por Microondas - Uma mistura do ácido 3,5dimetoxibenzóico $(10 \mathrm{mmol})$ e cloridrato de piridina $(50 \mathrm{mmol})$ foi colocada em um tubo de ensaio aberto e submetido à irradiação de microondas a $240 \mathrm{~W}$ por 1 minuto (20 pulsos de 1 minuto). Após cada irradiação, a reação foi resfriada a temperatura ambiente e re-irradiada. Após completa conversão da mistura reagente (monitorada por CCD), adicionou-se água e gelo e então foi extraída com acetato de etila. O extrato orgânico foi lavado com água, secado sobre sulfato de magnésio anidro e o solvente removido com vácuo. O produto foi purificado por cromatografia em coluna de sílica gel, usando-se hexano/acetato de etila 1:1.

Reação de podofilotoxina e podofilotoxona Assistida por Microondas - Uma mistura de podofilotoxina ou podofilotoxona $(10 \mathrm{mmol})$ e cloridrato de piridina $(50 \mathrm{mmol})$ foi colocada em um tubo de ensaio aberto e submetido à irradiação de microondas a $240 \mathrm{~W}$ por 1 minuto (20 pulsos de 1 minuto). Após cada irradiação, a reação foi resfriada a temperatura ambiente e re-irradiada. Após completa conversão da mistura reacional (observada por CCD), adicionou-se água e gelo e então foi extraída com acetato de etila. O extrato orgânico foi lavado com água, secado sobre sulfato de magnésio anidro e o solvente removido sob vácuo, para obter o produto. 


\section{RESULTADOS E DISCUSSÃO}

O nosso procedimento permitiu o isolamento e a purificação da podofilotoxina através de uma técnica de baixo custo e com considerável redução do tempo para obter o composto puro e efetuar os estudos semisintéticos desejados.

O processo associa o uso de amido de milho, recristalização e filtração cromatográfica simples. O procedimento sumariado na Fig. 2 é superior aos métodos existentes, comprovado pelo isolamento da podofilotoxina em rendimento quantitativo e com alto grau de pureza. Este processo é particularmente apropriado para separações em escala industrial, pois evita os métodos cromatográficos dispendiosos.

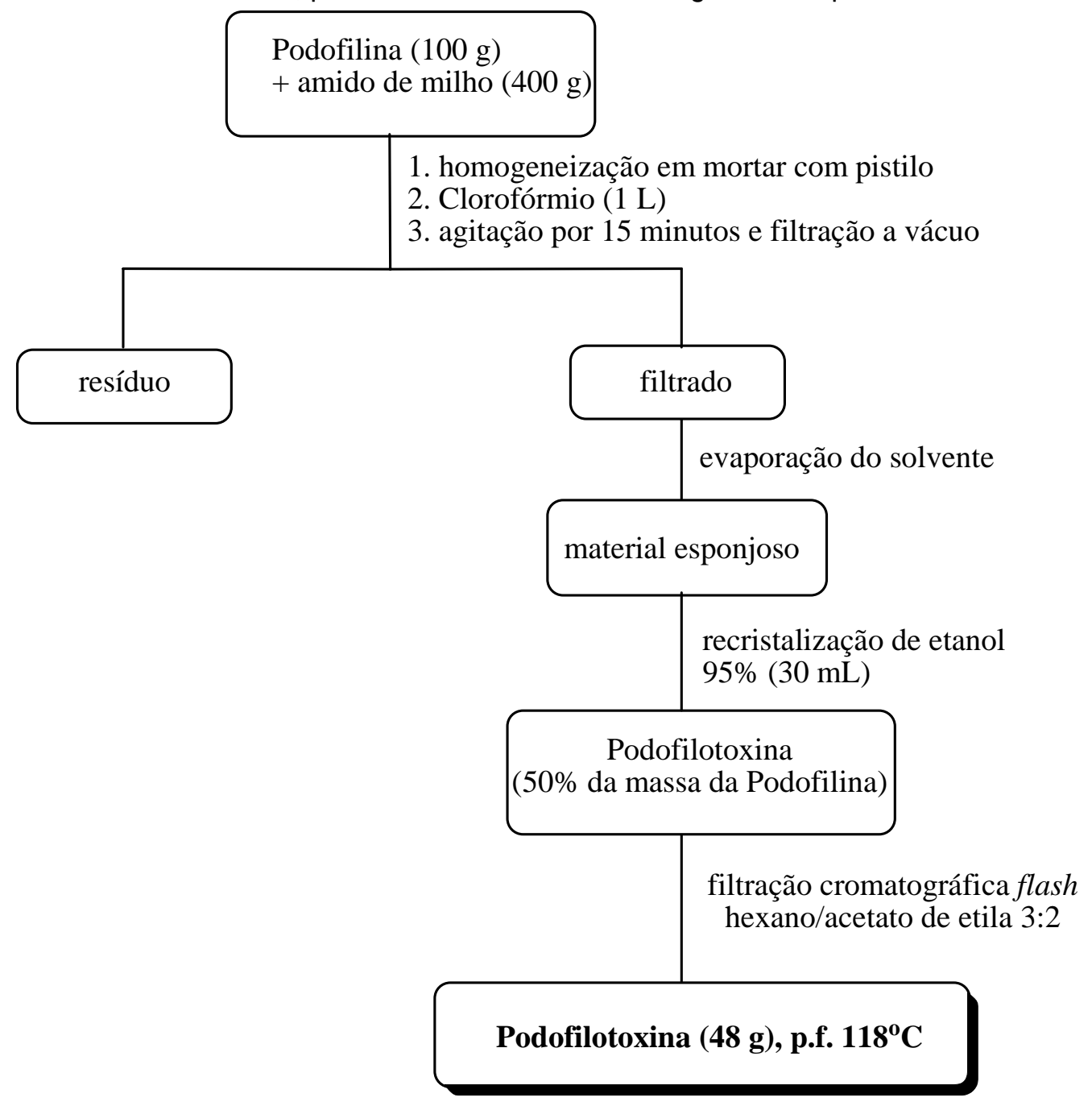

Figura 2. Fluxograma para separação da podofilotoxina do extrato de podofilina comercial.

Estudos em andamento em nosso laboratório visam desenvolver um método rápido, eficiente e seletivo para 4'-O-desmetilação no anel aromático na podofiloxina (1) e podofilotoxona (5) para em seguida preparar o etoposídeo (3) e compostos relacionados. Considerando a susceptibilidade do álcool benzílico para reações presente em 1, a desmetilação seletiva deve ser feita em condições muito brandas. Portanto, decidimos usar cloridrato de piridina e efetuar a reação sob irradiação de microondas (KULKARNI et al., 1999). Este reagente é bastante apropriado por ser facilmente disponível, de baixo custo e a reação pode ser feita sem qualquer solvente orgânico.

Em estudos recentes realizamos com sucesso reação modelo de monodesmetilação de um dimetiléter arílico, reagindo cloridrato de piridina com o ácido 3,5-dimetoxibenzoico (7) em tubo de ensaio aberto (MARIANO et al., 2003). A mistura foi irradiada em um forno de microondas comercial (240 W) por 1 minuto. Após a irradiação, a mistura reagente foi resfriada para temperatura ambiente e re-irradiada. A reação foi realizada em condições livre de solventes. A monodesmetilação foi completada em 20 minutos (20 pulsos) e o composto 8 foi obtido em bom rendimento (80\%). 
<smiles>COc1cc(OC)cc(C(=O)O)c1</smiles>

O sucesso nesta reação nos encorajou a tentar a desmetilação seletiva na posição 4' dos compostos 1 e 5. Como mostrado no Esquema 2, a irradiação de microondas ( $240 \mathrm{~W}$ ) sobre 1 não forneceu o produto desejado. No entanto, foi produzida a desidroanidropicropodofilotoxina (9) em bom rendimento (85\%). A podofilotoxona (5) foi preparada por oxidação com PCC de 1 (LIMA et al., 1994) e também submetida às mesmas condições de reação com microondas, fornecendo um produto de simples isomerização, a isopicropodofilona (10) em rendimento quantitativo (JACKSON \& DEWICK, 1984; RAHAMAN et al., 1995).

\section{Esquema 2}

1

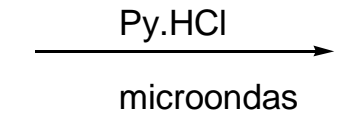

Py. $\mathrm{HCl}$

5<smiles>COc1cc(-c2c3c(cc4cc5c(cc24)OCO5)COC3=O)cc(OC)c1OC</smiles>

$9(85 \%)$<smiles>COc1cc([C@H]2c3cc4c(cc3C(=O)[C@@H]3COC(=O)[C@@H]32)OCO4)cc(OC)c1OC</smiles>

$10(100 \%)$

Os compostos 9 e $\mathbf{1 0}$ foram purificados por cromatografia em coluna de sílica gel e o dados espectroscópicos estão de acordo com os relatados na literatura (LIMA et al., 1994; JACKSON \& DEWICK, 1984; RAHAMAN et al, 1995).

\section{CONCLUSÕES}

Apresentamos aqui um método simples, rápido e altamente eficiente para isolamento e purificação da podofilotoxina a partir do extrato de podofilina e também algumas modificações químicas promovida por irradiação de microondas. O método desejado para desmetilação seletiva da podofilotoxina e podofilotoxona, usando Py. $\mathrm{HCl}$ sob irradiação de microondas e sem a presença de solvente, não foi bem sucedido. Os derivados desidroanidropicropodofilotoxina (9) e isopicropodofilona (10) foram obtidos. Em reação modelo, encontramos uma metodologia para desmetilação regiosseletiva do ácido 3,5-dimetoxibezóico (7).

\section{AGRADECIMENTOS}

Os autores agradecem ao CNPq, à Pró-Reitoria de Pesquisa e Pós-Graduação (PROPP-UFMS) e à Kardol Indústria Química Ltda pelo apoio financeiro e bolsas de estudos concedidas.

\section{REFERENCIAS}


AJANI, J. A; MANSFIELD, P. F.; DUMAS, P. Oral etoposide for patients with advanced gastric carcinoma. Cancer Journal. Science American, v. 5, p. 112-114, 1999.

DE AMBROSI, L. Rapid method of extraction of podophyllotoxin from resin of Podophyllum emody. II Fármaco, $v$. 9, p. 265-267,1954.

HORWTIZ, S. B.; LOIKE, J. D. A comparison of the mechanism of action of VP 16-213 and podophyllotoxin. Lloydia, v. 40, p. 82-89, 1977.

JACKSON, D. E.; DEWICK, P. M. Aryltetralin Lignans From Podophyllum hexandrum and Podophyllum peltatum. Phytochemistry, v. 23, p. 1147-1152, 1984.

KULKARNI, P. P.; KADAM, A. J.; MANE, R. B.; DESAI, U. V.; WADGAONKAB, P. P. Demethylation of methyl aryl ethers using Pyridine hydrochloride in solvent-free conditions under microwave irradiation. Journal of Chemical Research (S), p. 394-395, 1999.

LIMA, D. P. de; RASLAN, D. S; OLIVEIRA, A. B. New nitrogen derivatives of podophyllotoxin and a novel access to dehydroanhydropicropodophyllin. Synthetic Communications, v. 24, p. 2675-2683, 1994.

LOIKE, J. D.; HORWTIZ, S.B. Effects of podophyllotoxin and VP16-213 on microtubule assembly in vitro and nucleoside transport in HeLa cells. Biochemistry, v. 15, p. 5435-5442, 1976a.

LOIKE, J. D.; HORWTIZ, S.B. Effect of VP 16-213 on the intracellular degradation of DNA in HeLa cells. Biochemistry, v. 15, p. 5443-5448, 1976b.

MARIANO, V. G.; ANGREVES, G. M.; BEATRIZ, A.; LIMA, D. P. Studies Aiming the Synthesis of Demethyl Precursors of Etoposide. Revista Brasileira de Ciências Farmacêuticas, v. 39, Supl. 2, 2003.

MILLER R. A. Podophyllin. International Journal of Dermatology, v. 24, n. 8, p. 491-498, 1985.

PINTO, A. C.; SILVA, D. H. S.; BOLZANI, V. S.; LOPES, N. P.; EPIFANIO, R. A. Produtos Naturais: Atualidade, Desafios e Perspectivas. Química Nova, v. 25, supl. 1, p. 45-61, 2002.

RAHAMAN, A. U.; ASHRAF, M.; CHOUDHARY, I.; REHMAN, H.; KAZMI, M. H. Antifungal Aryltetralin Lignans From Leaves of Podophyllum hexandrum. Phytochemistry, v. 40, p. 427-431, 1995.

STÄHELIN, H. F.; VON WARTBURG, A. The chemical and biological route from podophyllotoxin glucoside to etoposide: ninth Cain memorial Award lecture. Cancer Researchm, v. 51, p 5-15, 1991.

VOGEL, A. I. Textbook of Practical Organic Chemistry. $5^{\text {th }}$ ed. Longman Scientific and Technical, 1967.

YONGJAE, Y. Podophyllotoxin Derivatives: Current Synthetic Approaches for New Anticancer Agents. Current Pharmaceutical Design, v. 11, p. 1695-1717, 2005. 